Int. J. Dev. Biol. 55: 569-581

doi: $10.1387 /$ ijdb.103186fm

\title{
Hypoxia and neural stem cells: from invertebrates to brain cancer stem cells
}

\author{
FERDINANDO MANNELLO ${ }^{*, 1}$, VIRGINIA MEDDA $^{1}$ and GAETANA A TONTI ${ }^{1,2}$ \\ ${ }^{1}$ Department of Biomolecular Sciences, Section of Clinical Biochemistry, Unit of Cell Biology, \\ University "Carlo Bo", Urbino, Italy and 'Natural Biosciences, R\&D Division, School of Biological Sciences, \\ The University of Reading, Whiteknights Reading, U.K.
}

\begin{abstract}
Oxygen is a fundamental element for all living organisms, and modifications in its concentration influence several physiological and pathological events such as embryogenesis, development and also aging. Regulation of oxygen levels is an important factor in neural stem cell biology (e.g. differentiation, growth and the capacity to generate more differentiated cells). Studies on neural stem cells in culture have deepened our knowledge of their survival, proliferation and differentiation pathways. However, traditional cell culture for neural stem cells is performed employing environmental oxygen levels of $20 \%$, while the effective oxygen concentration in the developing and adult brain is significantly lower; this results in an important alteration of the in vivo conditions. Several data indicate that a so called "physiologic hypoxic condition" could strongly influence the growth of neural stem cells and their differentiation mechanisms both in vivo and in vitro. The present overview deals with the different mechanisms utilized by invertebrate and vertebrate organisms to respond to hypoxic conditions. It highlights how the adaptations and responses to different oxygen concentrations have changed along the developmental route and underlines the importance of oxygen concentration in neural physiology and differentiation, with a final hint to the involvement of hypoxia in brain cancer stem cells.
\end{abstract}

KEY WORDS: central nervous system, development, differentiation, hypoxia, neural stem cell

\section{Hypoxia and oxygen sensing}

Oxygen is an essential element for most living organisms on earth, as it is a substrate for energy production and a regulator of cellular pathways. Evolutionary speaking, $\mathrm{O}_{2}$ has changed its nature from being toxic to becoming fundamental for living organisms, which need oxygen for fulfilling their metabolic activities. However, this may not always be the rule, as hypoxic condition (which may be conventionally considered harmful and deleterious) could actually overwhelm normoxic conditions in certain circumstance. In general, hypoxia is considered as a condition in which the body as a whole (generalized hypoxia) or a region of the body (tissue hypoxia) lacks adequate oxygen supply. A mismatch between oxygen supply and its demand at the cellular level may result in a hypoxic condition. Mammalian species, but not only, have developed complex systems to provide every cell of their body with sufficient $\mathrm{O}_{2}$ for their metabolic functions. In this review, we deal about the effects of hypoxic conditions in neural physiology and NSC biology, ranging from invertebrates to humans, evidencing how oxygen concentrations regulate a wide number of events, playing also a role in the development of brain cancer stem cells.

\section{Hypoxia-inducible factor (HIF)}

Hypoxia is a crucial developmental and physiological stimulus in a wide set of patho-physiological conditions and is involved in

Abbreviations used in this paper: AIF, apoptosis-inducing factor; ARNT, aryl hydrocarbon receptor nuclear translocator; bFGF, basic fibroblast growth factor; bHLH-PAS, basic-helix-loop-helix-PER-ARNT-SIM; DG, dentate gyrus; EGFR, epidermal growth factor receptor; EPAS 1, endothelial PAS domain-containing protein 1; Epo, Erythropoietin; ERK; extracellular signal-related protein kinases; FGF, fibroblast growth factor; HB-EGF, heparin-binding epidermal growth factor-like growth factor; HIF, hypoxia-inducible factor; HRE, hypoxia-responsive element; Hsp, heat shock protein; IGF, insulin-like growth factor; MAPK, mitogen-activated protein kinase; NPC, neural precursor cell; NSC, neural stem cell; ROS, reactive oxygen species; SGF, stem cell factor; SGZ, subgranular zone; STAT, signal transducers and activators of transcription; SVZ, subventricular zone; TGF, transforming growth factor; TH, tyrosine hydroxylase; VBC, VHL/elongin B/elongin C; VEGF, vascular endothelial growth factor; VHL, von Hippel-Lindau. *Address correspondence to: Prof. Ferdinando Mannello. Dipartimento di Scienze Biomolecolari, Sezione di Biochimica Clinica, Unità di Biologia Cellulare, Via O.
Ubaldini 7, Università Studi “Carlo Bo”, 61029 Urbino (PU), Italy. Fax: 39-0722-322370. e-mail: ferdinando.mannello @uniurb.it 
normal physiologic events, including neural stem cell differentiation and development "as reviewed in (Panchision, 2009)". The vast majority of multi-cellular organisms needs oxygen for survival, even though excessive concentrations of this element can cause the formation of toxic and highly reactive species (named reactive oxygen species, ROS). Accordingly, oxygen homeostasis is maintained in mammals through rapid behavioural and long-term physiological responses; the latter require the hypoxia-inducible factor (HIF) pathway, which is well conserved along all metazoans (Branicky and Schafer, 2008). HIF-1, together with the related transcription factors HIF-2 and HIF-3, is one of the main "oxygen sensing" factors (Fig. 1): it can promote or repress the transcription of a broad range of genes involved in maintaining biological homeostasis. The exposure to low levels of oxygen triggers a $\mathrm{HIF}-1$ response in virtually every vertebrate cell studied. HIF-1 is assembled from $\alpha$-subunits and from the constitutively expressed transcription factor ARNT/HIF-19, to become a transcriptionally active hetero-dimer; both subunits are members of the basic helix-loop-helix-PAS (bHLH-PAS) domain transcription factors and contain transactivation domains. The mRNAs encoding the "oxygen-destructible" HIF-1 $\alpha$ and "oxygen-indestructible" HIF-19 subunits have been detected in human and several other mammal tissues (Brahimi-Horn and Pouyssegur, 2009).
The expression of the HIF-1 $\alpha$ subunit (which is unique to HIF-1), is strictly regulated by $\mathrm{O}_{2}$ concentration in a way that the levels of HIF-1 $\alpha$ protein and HIF-1 DNA-binding activity increase exponentially as $\mathrm{O}_{2}$ concentration decreases. The HIF-19 subunit is less specific than HIF-1 $\alpha$ and can hetero-dimerize with other bHLHPAS proteins. HIF-1 transcriptional activity needs the inhibition of the post-transcriptional hydroxylation of the $\alpha$-subunit, which targets HIF for proteosomal degradation causing its inactivation. $\mathrm{HIF}-1 \alpha$ is regulated by post-translational prolyl hydroxylation of the oxygen-dependent degradation domain; prolyl hydroxylation directs the protein to proteosomal degradation via the interaction with von Hippel-Lindau (VHL) protein, a component of a multiprotein ubiquitin-ligase complex known as $\mathrm{VHL} /$ elongin B/elongin $\mathrm{C}$ (VCB). VCB then binds a chain of ubiquitin to HIF-1 $\alpha$, docking it onto the multi-subunit proteolytic complex, which degrades ubiquitinconjugated proteins "as reviewed in (Schofield and Ratcliffe, 2004). A VHL-independent regulation of HIF- $\alpha$ stability has also been suggested, as the heat shock proteins Hsp70 and Hsp90 protect HIF-1 $\alpha$ from proteosomal degradation. Both Hsp70 and Hsp90 are induced by hypoxia, controlling the activity and stabilizing HIF-1 $\alpha$, providing an alternative mechanism for hypoxia-induced HIF- $\alpha$ activation (Zhou et al., 2004). The complexity represented by $\mathrm{Hsp} 90$ lies in its involvement in the stabilization of conditionally

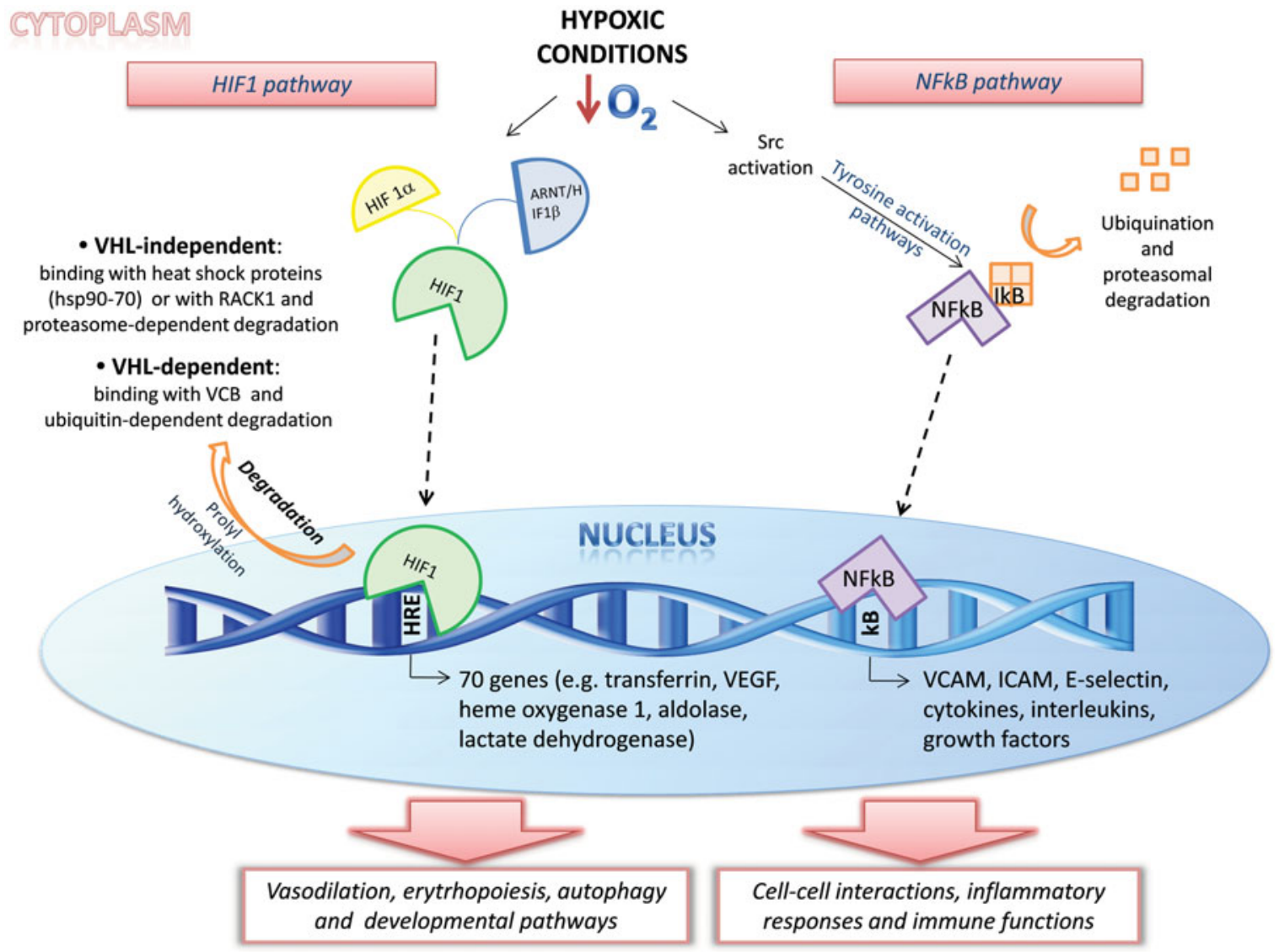

Fig.1. Schematic representation of the two most important pathways involved in oxygen sensing. In mammalian organisms oxygen homeostasis is maintained through rapid behavioural and long-term physiological responses that require the hypoxia-inducible factor (HIF) pathway. Another mechanism that regulates the adaptation to hypoxic conditions is represented by NFKB, a heterodimeric protein constitutively expressed, that once activated, translocates from the cytoplasm to the nucleus to activate gene transcription. The existence of different response mechanisms may suggest a cell-specific mode of signaling and regulation according to hypoxic microenvironment. 
activated and/or expressed signaling proteins in different events (such as cancer cell growth or survival, or both). Recently identified clients of Hsp90 include Akt and Her2, indicating the participation of this protein in signaling and chromatin-remodeling pathways. The receptor of activated protein C kinase (RACK1) has also been identified as a novel HIF- $1 \alpha$ interacting protein. The ubiquitination and degradation of HIF- $1 \alpha$ are promoted by RACK 1 , which is an essential component of the VHL-independent system for regulating HIF-1alpha stability; it acts through competition with Hsp90 and recruitment of the Elongin-C/B ubiquitin ligase complex (Liu and Semenza, 2007). Though oxygen-dependent regulation seems to provide the main control mechanisms of HIF function, receptormediated phosphorylation cascades (through the binding of various growth factors and cytokines) represent alternative ways to enhance HIF activity by translational and post-translational control in normoxic condition. While these pathways do not directly mediate the response to hypoxia, interactions with HIF signaling suggest that cellular responses to hypoxia can be fine-tuned by integration into major signaling systems (Zhou et al., 2004).

Under hypoxic conditions, prolyl hydroxylase domain proteins and HIF inhibiting factors are inactive due to insufficient oxygen. So, as oxygen levels decrease HIF- $1 \alpha$ gets stabilized and can rapidly translocate into the nucleus. HIF- $1 \alpha$ and HIF-19 interact with one another and bind to specific DNA hypoxia response elements (HREs) in the regulatory regions of target genes. The specific DNA sequences recognized by HIF are mainly found in the promoter, intron and/or enhancer regions of the targeted genes, like vascular endothelial growth factor (VEGF), glucose transporter 1, lactate dehydrogenase A and enolase 1 (Zhou et al., 2004). Once HIF is assembled on the HRE, it recruits transcriptional co-activators to form an intact initiation complex, a process mediated by distinct transactivation domains present within the HIF-1 $\alpha$ proteins. Additionally, there are phosphorylation and nitrosylation events that modulate HIF transcriptional activity, as well as numerous transcriptional co-activators and other interacting proteins providing cell and tissue specificity of HIF target gene regulation "as reviewed in. Manystudies identified more than 70 gene products containing HIF1 binding sites whose expression is increased by hypoxia, which are involved in metabolic pathways, vasodilation, erythropoiesis and autophagy (e.g., transferrin, vascular endothelial growth factor, heme oxygenase 1, aldolase, lactate dehydrogenase, etc) (Zhou et al., 2004).

Fig. 2. Effects of hypoxic conditions on neuronal physiological mechanisms in invertebrate organisms. An hypoxic environment leads to adaptations in neuronal physiology (in particular in ion concentrations) in different invertebrates, underlining the importance of this environmental factor in less evolved organisms.

\section{Molecular mechanisms involving $N_{K} B$}

Evidence has emerged for a second hypoxia-responsive pathway involving the transcription factor NFkB (Koong et al., 1994): this is a heterodimeric protein constitutively expressed, and once activated, translocates from the cytoplasm to the nucleus to activate gene transcription (Fig. 1). It is a member of the Rel-related proteins, which form dimeric DNA binding complexes at $k B$ sites (GGGANNTTCC). Rel-related proteins form a large number of dimeric complexes; inactive NFkB dimers are found in the cytoplasm and interact with an inhibitor protein IkB (a member of a family of regulatory proteins characterized by their multiple ankirin repeats and including $\mathrm{lkB}-\alpha$ and $\mathrm{Bcl} 3$ ). The inactive trimer reacts to stimulatory signals by targeted phosphorylation, subsequent ubiquitination and degradation of $\mathrm{IkB} \alpha$, allowing the NFkB dimer to enter the nucleus and bind to DNA. Genes regulated by NFkB include those involved in inflammatory responses and immune functions, such as cell adhesion molecules (VCAM, ICAM, E selectin, cytokine/growth factors, interleukin (IL)-2, IL-6, IL-8, and G-CSF) and c-myc. Hypoxia leads to increased NFkB DNA binding activity. The tyrosine phosphorylation of $\mathrm{lkB} \alpha$ inhibits its phosphorylation on serine residue preventing the activation of NFkB via the ubiquitination-degradation route, providing a proteolysis independent mechanism for NFkB activation. Activation of the proto-oncogene src occurs within 15 minutes of cellular exposure to hypoxia, and the downstream effectors of src, namely ras and raf, are involved in the tyrosine activation pathway of NFkB. Src activation is one of the earliest signaling events in the hypoxia response cascade leading to ras and raf- 1 kinase activation, and ultimately to tyrosine phosphorylation of $\mathrm{IkB} \alpha$ and NFkB activation (Koong et al., 1994). Only complexes that contain at least one of the strongly transactivating members of the Rel family (p65, etc) are efficiently regulated by $\mathrm{lkBa}$, and therefore activated. Homodimers of NFkB1-p50 or NFkB2-p52 may be controlled within the nucleus, as NFkB1-p50 and NFkB2-p52 subunits lack

\begin{tabular}{|c|c|c|}
\hline \multirow[t]{2}{*}{ INVERTEBRATES } & \multicolumn{2}{|c|}{ HYPOXIC CONDITIONS } \\
\hline & CAUSE & EFFECTS \\
\hline Planorbarius corneus & $\begin{array}{l}\text { No modification in neuron ion } \\
\text { concentrations }\end{array}$ & $\begin{array}{l}\text {-no membrane potential and conductivity } \\
\text { modifications }\end{array}$ \\
\hline Lymnaea stagnalis & $\begin{array}{l}\text { Reduction of intracellular } \\
\text { cation co-transporter activity }\end{array}$ & $\begin{array}{l}\text {-reduction of exicitatory GABAergic } \\
\quad \text { transmission } \\
\text {-hyper-polarization } \\
\text {-decrease of action of potential frequency } \\
\text {-induction of expression of HIF } 1 \alpha, \text { hsp } 70, \\
\quad \text { vesicle-associated membrane protein } 1 \\
\text {-repression of syntaxin } 1\end{array}$ \\
\hline Drosophila $n$ & Alteration of ion concentration & $\begin{array}{l}\text {-reduction of excitability } \\
\text {-large hyper-polarization } \\
\text {-induction of enzyme adenosine deaminase } \\
\quad \text { through ion channel editing }\end{array}$ \\
\hline Caenorhabditis elegans & $\begin{array}{l}\text { Stabilisation of HIF1 and } \\
\text { activation of egl-9/hif-1 } \\
\text { signalling }\end{array}$ & $\begin{array}{l}\text {-specific axon pathfinding } \\
\text {-neuronal migration defects }\end{array}$ \\
\hline
\end{tabular}


the IkB binding sequence and therefore cannot be retained in the cytoplasm. The association between IkB and NFkB is controlled by phosphorylation, which induces polyubiquitination, targeting the molecule for destruction. Cell type and differentiation state may dictate which system is operational. Hypoxia activates NFkB through a pathway that involves activation of IkB kinase-9 (IKK9); it is interesting to note that IKK9 contains an evolutionary conserved motif for hydroxylation by prolyl hydroxylases. Even though the consequences of hydroxylation are not fully understood it has been demonstrated that mimicking hypoxia or inhibiting this enzyme results in NFkB activation, suggesting a role for this enzyme in controlling the activity of NFkB (Cummins et al., 2006).

\section{Sometimes less is better than more, especially for neural stem cells}

Metazoans evolved sophisticated systems to ensure adequate oxygen supply to cells and tissues; they are able to sense when oxygen availability is insufficient, providing adaptive modifications that may enhance oxygen delivery or promote survival in hypoxic environment. As organisms evolved along the evolutionary route also the mechanisms used to respond to variations in oxygen conditions changed. to better understand the effects of hypoxia in NSC growth, proliferation and differentiation, and to widen our knowledge about the mechanisms underlying hypoxia-driven responses, it may be useful to go through the most important studies dealing with hypoxia and neural physiology/differentiation. For a comprehensive evaluation we start from the less evolved organisms, (i.e. Drosophila Melanogaster and Caenorhabditis elegans, as schematically represented in Fig. 2) throughout the mammalian organisms, ending up to humans.

\section{Hypoxic effects in invertebrate neuronal physiology}

Hypoxia leads to adaptation at all levels of neuronal physiology: from molecular, cellular, synaptic and functional levels, to neuronal network plasticity and behavioural learning There is literature data describing a number of phenomena that occur during $\mathrm{O}_{2}$ deprivation in invertebrates focusing on membrane function; however, practically absent are the informations on neural stem cells. Even though not strictly related to neural stem cells, we will report data evaluating hypoxic effects on invertebrate neuronal systems. Although it is well known that genes can be regulated by low $\mathrm{O}_{2}$, it is neither clear how many genes are regulated by hypoxia nor is it known how many of these genes are specifically important for surviving $\mathrm{O}_{2}$ deprivation.

The role of oxygen reduction has been studied mostly for its effects on cation concentrations (e.g. K and $\mathrm{Na}$ ), membrane potential and conductivity in neurons. Anoxia in the freshwater snail Planorbarius corneus doesn't modify ion concentrations in the neurons, and inhibition of oxygen uptake by ganglia doesn't affect the membrane potential and conductivity in neurons (Skul'ski, 1991). On the other hand, a study performed on neurons from the isolated central ring ganglia of the pond snail Lymnaea stagnalis shows that severe hypoxia reduces the activity of the intracellular cation co-transporter, leading to a reduction in excitatory GABAergic transmission; these modifications result in a hyper-polarization of the resting membrane potential and a decreased action of potential frequency. Evaluating neural behaviour and presynaptic protein expression in Lymnaea stagnalis, demonstrated that hypoxia induces the expression of stress-response proteins, HIF-1 $\alpha$ and hsp-70, represses syntaxin-1 (a membrane-bound presynaptic protein) and increases vesicle-associated membrane protein-1. Electrophysiological measurements from interneurons shows that hypoxia increases the frequency of spontaneous postsynaptic excitatory potentials, but reduces the firing frequency, the amplitude and the half-width duration of spontaneous action potentials (Silverman-Gavrila et al., 2009).

Compared to mammalian species, Drosophila Melanogaster is strongly tolerant to oxygen deprivation. Astudy evaluating the effect of hypoxia on neuronal excitability using neurons from embryonic cultures of the fruit-fly evidenced that 1) Drosophila neurons in culture show a decrease in their excitability with hypoxia, 2) over several minutes, hypoxia induces a large hyper-polarization in Drosophila neurons, which contrasts with previous findings on mammalian neurons when exposed to hypoxia, 3) and hypoxic stress is similar in its effects on rat, but has opposite effects on Drosophila neurons (Gu and Haddad, 1999). Drosophila neurons reduce their input resistance significantly and hyperpolarize strongly during hypoxia; this could be a reason for the decrease in excitability. These data demonstrate that Drosophila neurons use different mechanisms when exposed to a critical stress like hypoxia, compared to mammals (Gu and Haddad, 1999). A further study using Drosophila reported that through the editing of ion channels, the enzyme adenosine deaminase (expressed almost exclusively in the adult central nervous system and for which there are mammalian homologues), is essential for adaptation to altered environmental stresses such as oxygen deprivation.

The human hypoxia-inducible transcription factor together with its regulatory pathway is evolutionary conserved, and Caenorhabditis elegans hif-1 and vhl-1 genes encode homologs of the human subunits (Chang and Bargamann, 2008). Hypoxia causes specific axon pathfinding and neuronal migration defects in Caenorhabditis elegans, resulting from the stabilization of the transcription factor HIF-1 in neurons. Hypoxia-mediated defects in nervous system development depend on signalling through the insulin-like receptor DAF-2; this receptor controls the level
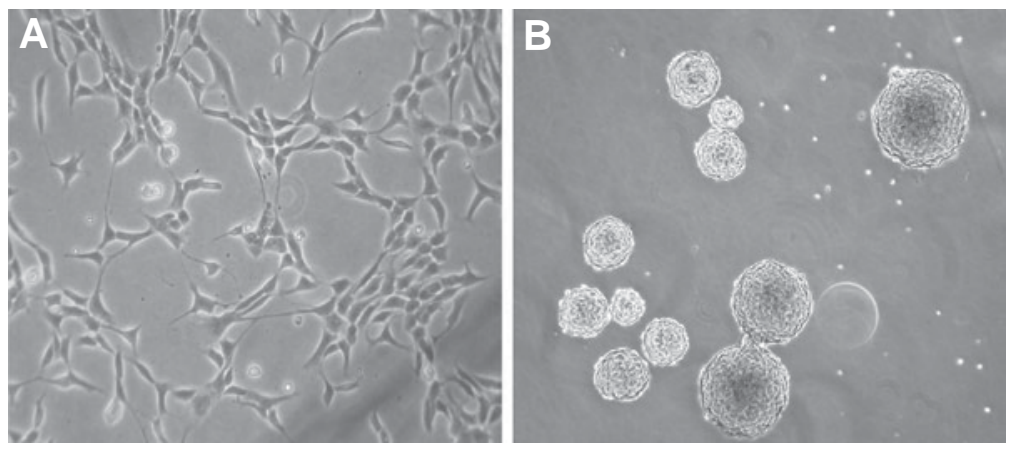

Fig. 3. In vitro culture of neural cells (A) and neurospheres (B) isolated from subventricular zone of adult mice. Both cell types were cultured in vitro in the presence of EGF $(20 \mathrm{ng} / \mathrm{ml}), b F G F(10 \mathrm{ng} / \mathrm{ml})$ and $\mathrm{N} 2$ supplement, allowing neural stem cell proliferation. To avoid stem cell differentiation, the adhesive cells (A) were cultured on dishes coated with polyornithine $(10 \mathrm{ug} / \mathrm{ml})$ and laminine $(2,5 \mathrm{ug} / \mathrm{ml})$, maintaining them in low density conditions (about 50-60\% respect to confluence) (Cacci et al., 2007). 
of ROS that affects pathfinding, influenced by HIF-1-dependent regulation of the Eph receptor. Similar genetic pathways may lead to wrong human brain development under hypoxic conditions. Caenorhabditis elegans exhibits avoidance responses to hypoxia as well as hyperoxia; the hyperoxia avoidance is mediated by a distributed network of sensory neurons: nociceptive neurons, serotonergic neurons and oxygen-sensing neurons that express oxygen-binding soluble guanylate cyclases. Prolonged growth in hypoxia modifies the neuronal circuitry for oxygen preference by activating hif-1 pathway; this activation of hif- 1 by hypoxia shifts behavioural oxygen preference into a smaller, fixed network that is constitutively active. The hif- 1 pathway acts both in neurons and in gonadal endocrine cells that regulate oxygen preference; the modified preference results from activation of the hif- 1 pathway in both neurons and non-neuronal cells, leading to reorganization of the neuronal circuit (Chang and Bargamann, 2008). The use of HIF-1 to modify oxygen preferences is a way to match physiological needs and behavioural priorities; Caenorhabditis elegans adapts to various environmental conditions by developing HIF-1 in hypoxia and antioxidant enzymes in hyperoxia. In particular, adaptations to hypoxia and hyperoxia provide a rationale for the enhanced avoidance of hyperoxia after cultivation in hypoxia (Chang and Bargamann, 2008). In Caenorhabditis elegans the molecular targets of egl-9/hif-1 that regulate cellular sensing are unknown, even though they may be several. The most evident effect of egl-9/hif-1 pathway is the reorganization of neuronal contributions to oxygen preference.

It's amazing how these results demonstrate that a modification in the environment can uncover alternative circuits within the apparently fixed anatomy of the nervous system even in the so called "less evolved organisms".

\section{How hypoxia influences neural stem cells in vertebrate or- ganisms}

The CNS has traditionally been viewed as a system with a very limited capacity for self-renewal and regeneration; however, in certain brain regions, NSCs exist and give rise to new neurons as part of an endogenous turnover mechanism. In the adult brain there are two regions where neurogenesis takes place throughout life: the subependymal or subventricular zone (SVZ) of the later ventricle and the subgranular zone (SGZ) of the dentate gyrus (DG) in the hippocampus. During adult life, new neurons from the SVZ migrate through the rostral stream into the olfactory bulb where they complete their differentiation process. New neurons originating from the SGZ are continuously added into the granular cell layer of the DG. The newly generated neurons have the capacity of migrating and integrating the pre-existing circuits of the CNS contributing to specific brain functions (Doetsch and Hen, 2005). The multipotentiality of NSCs is mediated by the generation of cell-lineage restricted intermediate progenitors that produce only neurons (neuronal progenitors) and glial progenitors that produce only astroglial physiology. or oligodendroglial cells. Unlike the predominantly neurogenic adult SVZ, the neonatal SVZ gives rise to both neurons and glia; whereas the adult SVZ contains tripotent NSCs (i.e. proliferating neuroblasts, and a small proportion of glial precursors), the neonatal SVZ contains multipotent stem cells (i.e. neuroblasts that generate interneurons, and glial progenitors that generate astrocytes and oligodendrocytes) (as reviewed in Tonti et al., 2009).NSCs can differentiate into neurons, astrocytes and oligodendrocytes. They undergo symmetric divisions, expanding the stem cell pool; subsequently, they initiate asymmetric divisions generating a committed neuronal precursor cell as well as another daughter cell identical to the parent. The committed neuronal cell may instead undergo one or more further symmetrical divisions before differentiation, and is therefore a precursor cell (analogue to the transit amplifying cells in many adult lineages) rather than a stem cell.

Under in vitro conditions, and in the presence of specific growth factors (such as fibroblast growth factor 2 and/or epidermal growth factor), neural stem/progenitor cells isolated from both embryonic and adult neurogenic regions can proliferate and if plated on uncoated plastic surface form dividing clusters of cells called "neurospheres". This mechanism of expansion is an interesting and useful tool to culture and evaluate neural stem cell properties (Singec et al., 2006): starting from an heterogeneous primary culture, it leads to death of committed or more differentiated mature cells, and positive selection of undifferentiated NSCs (which proliferate initially as adherent cells and give rise to spherical clusters that float in suspension: the so called "neurospheres") (Fig. 3) (Studer et al., 2000; Cacci et al., 2007).

\section{"Of mice and men"}

Neurogenesis is also modulated by pathological conditions as it is increased by epileptic seizures, global ischemia, and brain trauma, as well as by conditions of oxygen deprivation. In this respect, fine-tuning of oxygenation is particularly interesting

\begin{tabular}{|c|c|c|}
\hline \multicolumn{3}{|c|}{ INVOLVEMENT OF HYPOXIA IN MURINE PHYSIOLOGIC MECHANISMS } \\
\hline \multirow{3}{*}{$\begin{array}{l}\text { NEURAL } \\
\text { STEM CELL }\end{array}$} & PROLIFERATION & $\begin{array}{l}\text { - promotion of proliferation } \\
\text { - reduction of apoptosis } \\
\text { - increase in precursor number } \\
\text { - elevation of Epo expression with Mash1 protein } \\
\text { - increase of HB-EGF, HIF1 and VEGF expression } \\
\text { - elevation of SCF stimulating signal transduction } \\
\text { pathways (e.g., Src, JAK/STAT, Ras-Raf-kinase) }\end{array}$ \\
\hline & DIFFERENTIATION & $\begin{array}{l}\text { - JNK and ERK signaling and ERK1 and Akt activation, } \\
\text { leading to generation of neurons and glia } \\
\text { - increase of proportion of NPCs competent to produce } \\
\text { neurons and oligodendrocytes } \\
\text { - differentiation and production of dopaminergic neurons } \\
\text { with VEGF } \\
\text { - involvement in sympathoadrenal lineage capacity via } \\
\text { tyrosine hydroxylase increase } \\
\text { - switch from GABA-positive to glutamate-positive neurons }\end{array}$ \\
\hline & SURVIVAL & $\begin{array}{l}\text { - inibition of AIF-dependent cell death in primitive NSCs } \\
\text { - attenuation of caspase-mediated apoptosis in definitive } \\
\text { NSCs } \\
\text { - up-regulation of Epo, Epo receptor, bcl-2 and } \\
\text { synaptophysin }\end{array}$ \\
\hline $\begin{array}{l}\text { NEURAL } \\
\text { PRECURSOR }\end{array}$ & MIGRATION & $\begin{array}{l}\text { - up-regulation of VEGF, stromal-derived growth factor } 1 \alpha \text {, } \\
\text { SCF and monocyte chemoattractant protein-1 }\end{array}$ \\
\hline
\end{tabular}

Fig. 4. Neural Stem Cell (NSC) physiology. Main effects of hypoxic condition on murine NSC 
for NSC viability and function; the cells of the nervous system are capable of sensing changes in oxygen tension, and oxygen changes have complex but poorly understood effects on precursor cell fate in both murine and human models (Fig. 4 and 5, respectively). Oxygen values in the CNS are similar among all adult mammalian species tested and range from $0,55 \%$ in the midbrain to $8 \%$ in the pia mater; the measured $\mathrm{O}_{2}$ level of the cortex is $2-5 \%$. Dynamic modifications of oxygen availability may be an important component of the NSC niche, as oxygen sensing is integrated into the normal regulatory pathways for NSC proliferation and fate choice "as reviewed in (Panchision, 2009)". Traditional NSC culture is performed in non-physiologically high $\mathrm{O}_{2}$ concentration; in fact, standard tissue culture incubator conditions expose cells to a $20 \% \mathrm{O}_{2}$ environment. On these basis, many studies have been performed to evaluate the effects of culturing CNS progenitor cells in "physiological" lowered $\mathrm{O}_{2}$ levels, as well as in different oxygen conditions (e.g. intermittent hypoxia, acute hypoxia) (Fig. 6). Generally most studies are performed in chronic hypoxic conditions, which consists of exposing cells/tissues to low oxygen concentration (from 1 to $5 \%$ of environmental oxygen) for a long time period (in the range of 3-6 days). Differently, transient hypoxia is referred to as an exposure to low oxygen condition lasting few hours, usually from 2 to 6 hours. Also anoxia (using sterile hypoxia chambers, where cells are kept in these conditions from 48 to more than 150 hours) are utilized. Experiments have also been performed with intermittent hypoxia: the most utilized models correspond to repeated episodes of hypoxia, lasting from a few seconds to a few hours interspersed with episodes of normoxia. The actual protocols used for intermittent hypoxia vary greatly in cycle length, number of hypoxic episodes per day and number of days. Regardless of the protocol, the compelling outcome is that these repeated episodes of hypoxia elicit persistent changes in a variety of physiological responses, suggesting that there is a cumulative effect of intermittent hypoxia that begins with the first exposure to hypoxia.

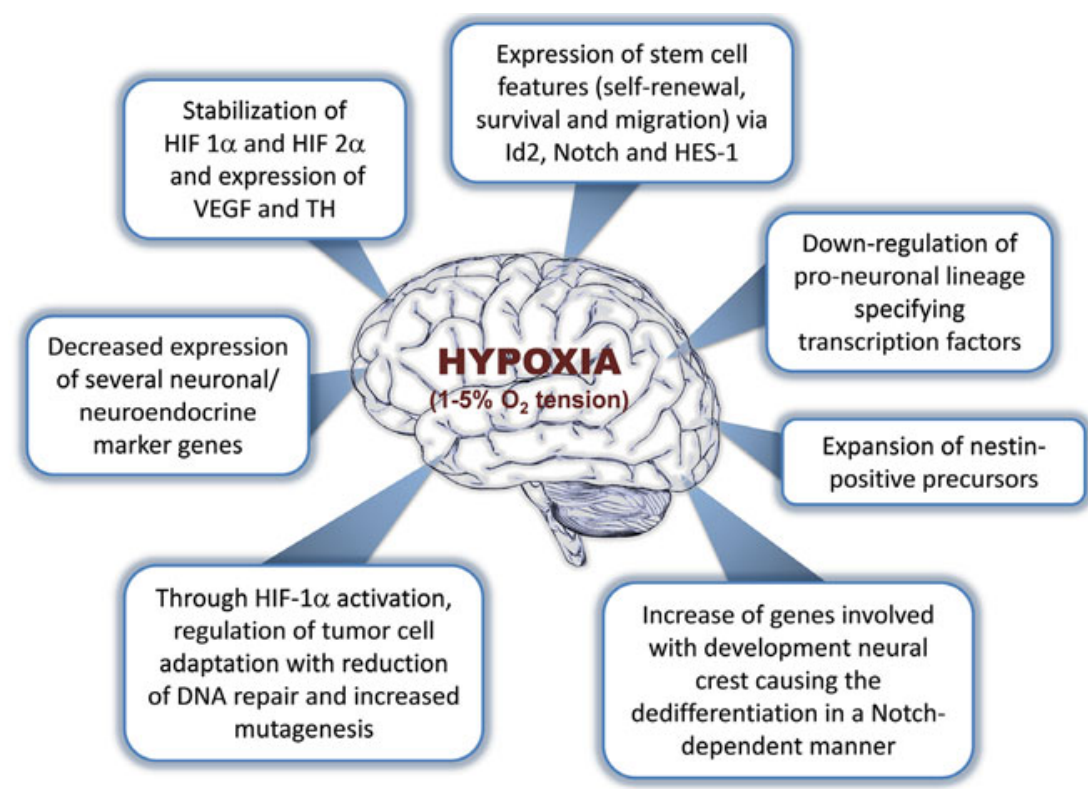

Fig. 5. Representative diagram of the adaptations of subsets of neurons to hypoxic conditions.

\section{The effects of hypoxic condition in murine neural stem cells Neural stem cell proliferation}

One of the first studies analyzing the impact of lowered $\mathrm{O}_{2}$ levels on CNS stem cell culture took into consideration rat CNS precursors, reporting that in lowered $\mathrm{O}_{2}$ conditions (cultures where placed in humidified isolation chambers, flushed with a gas mixture containing $1 \% \mathrm{O}_{2}$ obtaining a range ambient of $\mathrm{O}_{2}$ of $3 \pm 2 \%$ ), proliferation was promoted, while apoptosis was reduced, yielding a greater number of precursors. The increase in cell number was observed during the proliferation phase when most of the cells were nestin-positive precursors; the increase in cell number was maintained after mitogen withdrawal when proliferation was overall vastly reduced (Studer et al., 2000). Two growth factors, FGF and Epo, were identified as candidates for significant roles in the response to lowered $\mathrm{O}_{2}$ condition. Epo is produced in the brain as a part of the intrinsic hypoxia response and its receptors are expressed in areas of the CNS which continue to generate neurons throughout adulthood (Shingo et al., 2001). Cultured NSCs obtained from neurospheres of embryonic and adult mouse forebrains exposed to hypoxic conditions produced two-to three-fold more neurons together with an elevation in Epo gene expression. It seems that Epo acts directly on NSCs, promoting the production of neuronal progenitors at the expense of multipotent progenitors; this process is associated with an elevation of Mash1 protein in NSC cultures (Shingo et al., 2001). In vivo studies also demonstrate that Epo regulation of NSC-dependent neurogenesis in the olfactory bulb does not only regulate neuron output, but it rather regulates the relative number of NSCs and neuronal progenitors (Shingo et al., 2001), suggesting that Epo influences the restriction of multipotent NSCs to the neuronal lineage.

There are several factors released during hypoxia that can stimulate neurogenesis in vitro. Heparin-binding epidermal growth factor-like growth factor (HB-EGF) is one such factors and acts via the EGF receptor; hypoxia increases HB-EGF expression in embryonic mouse cortical cultures and in adult brain (stimulating neurogenesis in the SVZ and $S G Z$ ), and its expression is associated with mature and immature neurons (Jin, et al., 2002b). Hypoxia-conditioned medium and SCF stimulated neurogenesis in mouse cerebral cortical cultures. SCF receptor was expressed in neuronal cultures and in neuroproliferative areas of the adult brain indicating that SCF stimulates neurogenesis in vivo; it produced biological effects via c-kit activation, leading to receptor homo-dimerization and autophosphorylation, and stimulating signal transduction pathways involving Src, JAK/STAT, and Ras-Rafkinase (Jin et al., 2002a). The beneficial effect of continuous exposure to $1 \% \mathrm{O}_{2}$ condition on cortical neuron survival and development is associated with HIF-1 up-regulation and is mediated also by the neuroprotective effects of VEGF, suggesting that neurons themselves are the source of the useful secreted factors. So, rather than harming neurons, hypoxia enhances survival of embryonic cortical neurons, improving neuronal viability and robust neuronal dendritic development, indicating that oxygen tension may be an important compo- 
nent of the NSC niche (Jin, et al., 2002a). Regional progenitors exhibit distinct profiles of cellular proliferation and differentiation in response to hypoxia $\left(1-5 \% \mathrm{O}_{2}\right)$, and intermittent hypoxia induces transient increases in progenitor cell proliferation in the SVZ and a long-term increase in the DG, suggesting the existence of different NSC sub-types.

To evaluate whether mild hypoxia may be useful for expansion of embryonic NPCs in vitro and if HIF-1 $\alpha$ may be the causative molecule in this process (as downstream targets of hsp90 inhibitors), it has been shown that geldanamycin (a specific heat shock protein inhibitor) decreases the expression of HIF- $1 \alpha$ in NPCs during hypoxia-driven proliferation $\left(3 \% \mathrm{O}_{2}\right)$ and reduces the expression level of HIF- $1 \alpha$ protein under hypoxia in a timedependent manner; this suggests that Hsp90 might be involved in the regulation of hypoxia-driven proliferation (Xiong et al., 2009). In addition, ARNT2 (a conserved ARNT homolog) is highly expressed in neurons and forms functional HIF complexes in vivo regulating hypoxia-induced gene expression, thus being directly responsible for the neural response to hypoxia (obtained culturing cells in an atmosphere of $\left.93,5 \% \mathrm{~N}_{2} / 5 \% \mathrm{CO}_{2} / 1,5 \% \mathrm{O}_{2}\right)$. However, ARNT2 may have much more complicated implications: while the role of ARNT as a general partner factor for bHLH/PAS proteins (such as HIF) has been well characterized, the physiological role for an ARNT homodimer in the absence of stimuli which activate formation of an ARNT heterodimer has yet to be fully investigated (Kewley et al., 2004).

Studies evaluating perinatal hypoxia through neurospheres have demonstrated that this condition increases proliferation of cells that are positionally and phenotypically neural precursor cells. Twice as many NPC-derived neurospheres were generated by the hypoxic SVZ, and the precursors within these neurospheres exhibited more frequent symmetric divisions with multi-potential behaviour. These NPC-derived neurospheres express markers of immature multipotent precursors (nestin), but not markers of more restricted progenitors (PSA-NCAM), revealing that perinatal hypoxia $\left(8 \% \mathrm{O}_{2}\right)$ induces the expression of multiple genes within the SVZ, able to influence cell stemness (such as EGFR, Notch, Hes5) (Felling et al., 2006).

\section{Neural differentiation}

Oxidant stresses (and in particular hypoxia) induce signal transduction pathways that activate transcription factors, determining cell fate. The mitogen-activated protein kinases (MAPK), including the extracellular signal-related protein kinases (ERK) and the stress activated kinases, c-Jun and p38 MAP kinases, regulate neural cell proliferation and differentiation programs, as well as activation of apoptosis cascades. Mouse hippocampal organotypic cultures represent an informative model to analyze the temporal sequence of intrinsic responses to transient hypoxic stress. In this respect, hypoxia ( $2 \%$ of oxygen ambient levels) triggers JNK, c-Jun and ERK signalling, and (after reoxygenation) ERK1 activation and stem cell proliferation activating quiescent NPCs leading to their amplification and subsequent differentiation into neurons and glia (Zhou and Miller, 2006). ERK and Akt were transiently activated in NPCs exposed to hypoxia/regeneration (maintaining cells under hypoxic conditions in chambers with gas mixtures of $95 \% \mathrm{~N} / 5 \% \mathrm{CO}_{2}$ ), suggesting that hypoxia/ reoxygenation induced the activation of ERK and PI3K/Akt survival signalling pathways through a PKC-dependent mechanism
(Sung et al., 2007). On the other side, the condition of $21 \% \mathrm{O}$ induced neurosphere attachment and flattening, expression of cell adhesion molecules, together with ongoing cellular maturation, aging of the culture and terminal differentiation. Neuronal, glial and neurogenesis-related markers were up-regulated in NPCs at $21 \% \mathrm{O}_{2}$, while low oxygen concentrations prevented terminal differentiation. Lowered oxygen $\left(8 \% \mathrm{O}_{2}\right)$ also prevented neuronal differentiation of rat NPCs, as measured by 911 -tubulin expression (Gustafsson et al., 2005) and increased the proportion of NPCs competent to produce neurons and oligodendrocytes in vitro, increasing striatal and neocortical neurogenesis in vivo.

To determine the role of HIF- $1 \alpha$ in proliferation, survival and dopaminergic differentiation in vitro, as well as survival of murine dopaminergic neurons in vivo, HIF-1 $\alpha$ was conditionally inactivated in murine neural precursor cells (NPCs). HIF- $1 \alpha$ knock-out NPCs showed midbrain-specific impairment of survival and proliferation, and dopaminergic differentiation in vitro was markedly reduced, as well as expression of VEGF mRNA (Milosevic et al., 2007). In hypoxic conditions $\mathrm{HIF}-1 \alpha$ may be a transcription factor relevant to the development and survival of dopaminergic neurons involving VEGF signalling. HIF- $1 \alpha$ in some way regulates the differentiation and production of dopaminergic neurons (Kim et al., 2008) and hypoxia $\left(3-10 \% \mathrm{O}_{2}\right.$ vs $20 \% \mathrm{O}_{2}$ ) might promote dopaminergic differentiation in the proliferation but not in the differentiation phase (Zhang et al., 2006). In light of the studies evaluating the production of dopaminergic neurons from precursor cells (e.g. for transplantation in Parkinson's disease), it has been shown that murine mesencephalic neurospheres were viable and proliferated, preserved telomerase activity, pluripotency and dopaminergic commitment when cultured in $3 \% \mathrm{O}_{2}$, whereas exposing these cell to $21 \% \mathrm{O}_{2}$ prohibited long-term expansion (Milosevic et al., 2007). Several genes related to cell cycle, cell maturation and apoptosis were differentially regulated in these midbrain-derived precursors, suggesting that high oxygen (such as $20 \%$ ) has deleterious effects on the self-renewal capacity of mesencephalic neural precursors, possibly accelerating maturation and senescence. The oxygen reduction from high $(20 \%)$ to low condition (1-3\%) drastically enhances projective neuronal differentiation, such as dopaminergic differentiation of CNS precursors in vitro.

Culturing NSCs in reduced oxygen environment revealed an essentially uniform sympathoadrenal lineage capacity. The effect of decreased oxygen concentration in increasing tyrosin hydroxylase (TH) expression by NSCs (most $\mathrm{TH}+$ cells might represent immature sympathoadrenal progenitors) may be mediated by the

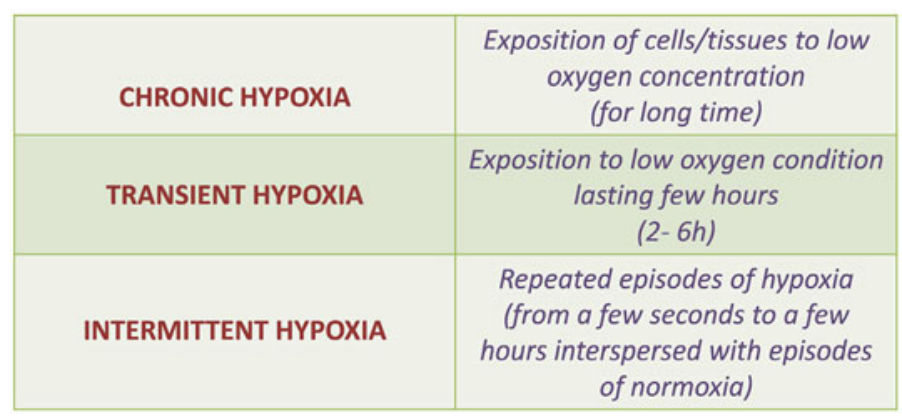

Fig. 6. Description of the most common hypoxic conditions utilized in CNS progenitor cell culture. 
bHLH-PAStranscription factor EPAS1 (known as HIF-2 $\alpha$ ), that binds to an essential hypoxia-responsive element in the $\mathrm{TH}$ promoter, required for the development of noradrenergic cells. Finally, lowered oxygen conditions $\left(2 \% \mathrm{O}_{2}\right)$, enhanced the switching of the neuronal subtype differentiation from GABA-positive to glutamate-positive neurons (Horie et al., 2008). In contrast to low oxygen concentrations, anoxia (i.e. $0 \%$ oxygen tension) failed to affect proliferation and neural differentiation of the NSCs, and rather increased cell death when compared to $20 \%$ oxygen concentration.

\section{Neural stem cell survival}

A challenge in culturing primitive NSCs is trying to reduce the extensive cell death that occurs when these cells are placed into minimal, serum-free conditions. A potential method for alleviating cell death in embryonic-derived NSCs is the use of low-oxygen conditions which has positive effects on survival and proliferation. In this respect, it isimportant whether low oxygen culture for embryonic-derived NSCs may attenuate cell death when the stem cells are placed into the neural colony-forming assay. Primitive NSCs (clonally derived from embryonic stem cells) are normally subject to caspase9-dependent apoptosis (as well as AIF-mediated cell death); clonal definitive NSCs are also subject to caspase-dependent cell death but require AIF for their survival. Inhibition of AIF-dependent cell death occurs when primitive NSCs are cultured in low-oxygen conditions $\left(4 \% \mathrm{O}_{2}\right)$, but in definitive NSCs low oxygen attenuates caspase-mediated apoptosis (Clarke and Van Der Kooy, 2009). These data elucidate how different cell death pathways are involved in the response to variable oxygen concentrations in sequential NCS populations.

Low oxygen conditions (such as 5\%) permitted clonal and long-term expansion of mouse foetal cortical precursors, while $20 \%$ oxygen led to a rapid decrease in HIF-1 $\alpha$, followed by induction of p53 and apoptosis. These modifications decreased the overall cell number and caused a loss of astrocytes and oligodendrocytes. Apoptosis in $20 \%$ oxygen was due to a complete loss of $\mathrm{CD} 133^{\mathrm{lo}} \mathrm{CD} 24^{\mathrm{lo}}$ multipotent precursors, a substantial loss of $\mathrm{CD} 133^{\text {hi }} \mathrm{CD} 24^{\text {lo }}$ multipotent precursors, and a failure of remaining CD133 ${ }^{\text {hi } C D 24}{ }^{\text {lo }}$ cells to generate glia. Although committed neuronal progenitors were not significantly affected at $20 \%$ oxygen, they survived equivalently in either $5 \%$ or $20 \%$ oxygen, and bipotent glial and oligodendrocyte progenitors were not generated in large numbers until bFGF was removed. Multipotent cells and oligodendrocyte progenitors are more susceptible to apoptosis at $20 \%$ oxygen than committed neuronal progenitors, representing important implications for optimizing ex vivo production methods for cell replacement therapies (Chen et al., 2007).

The effect of anoxia on cell survival was studied on adult rat NSC in vitro, with a reduction of caspase activity and an increase in proliferation, cell number and NSC, resulting in a highly stimulating environmental factor (Bürgers et al., 2008).

Taking into consideration hypoxic preconditioning (i.e. a transient phenomenon induced by brief episodes of sub-lethal hypoxia that activates various endogenous trophyc signals), sub-lethal in vitro hypoxia pre-treatment significantly increased the tolerance of neurally-differentiating embryonic stem cells to apoptotic death. Hypoxic preconditioning $\left(1 \% \mathrm{O}_{2}\right)$ up-regulated expression of Epo, Epo receptor, bcl-2, HIF-1 $\alpha$, neurofilament and synaptophysin in embryonic-derived neural progenitor cells, accompanied by reduced caspase-3 activation (Theus et al., 2008).

\section{Neural precursor cell migration}

An interesting topic is if and how hypoxia-induced astrocytes could affect the migration of NPCs and the possible expression of some chemokines. Hypoxia up-regulated VEGF, stromal-derived growth factor- $1 \alpha$, SCF and monocyte chemoattractant protein-1 in a time-dependent manner in rat astrocytes exposed to hypoxia, and the time peak of expression of these chemokines was similar to the time point of maximum NPC migration. When the chemokines were inhibited independently, NPC migration was reduced while when they were inhibited together, NPC migration was more strongly inhibited, suggesting that soluble factors released from astrocytes direct the migration of NPC under hypoxic $\left(1 \% \mathrm{O}_{2}\right)$ circumstances (Xu et al., 2007).

\section{Hypoxia in human neural stem cells}

For what concerns human NSCs, neuroblastoma cell lines are commonly used as models to study the differentiation and development of neural cells in vitro. In these cell lines hypoxia $\left(1-5 \% \mathrm{O}_{2}\right)$ stabilizes HIF-1 $\alpha$ and HIF-2 $\alpha$ proteins and activates the expression of known hypoxia-induced genes, such as VEGF and tyrosine hydroxylase. Hypoxia also decreases neuronal/neuroendocrine marker genes and up-regulates genes expressed during normal development of the neural crest, apparently causing dedifferentiation. Many of the genes expressed in hypoxic neuroblastoma cells determine the presence of stem cell features, such as selfrenewal, survival and migration. Although the initiating molecular events leading to dedifferentiation have not been explored, the hypoxia-induced expression of Id2, Notch-1 and HES-1 has been suggested to contribute to the hypoxia-provoked dedifferentiation of neuroblastoma cells and the development of a non-neuronal phenotype (Jögi, et al., 2004). Hypoxia causes a general adaptive response in neuroblastoma cells, confirming the loss of neuronal phenotype and gain of stem-cell characteristics. Neuroblastoma cells grown at $5 \%$ oxygen stabilize HIF- $2 \alpha$ but not HIF- $1 \alpha$, and hypoxia-induced genes (e.g. TH and Id2) are slightly up-regulated; these data suggest that HIF-2 $\alpha$ could be transcriptionally active at $5 \%$ oxygen and that the phenotype of neuroblastoma cells grown at this normoxic condition is to a certain extent determined by HIF-2 $\alpha$ (Axelson et al., 2005). The different mechanisms for regulating $\mathrm{HIF}-1 \alpha$ and $\mathrm{HIF}-2 \alpha$ levels in response to oxygen deprivation (protein stabilization and increased transcription, respectively) may reflect diverse roles and lineage-specific expression/regulation of these proteins.

In vitro expansion of human postnatal brain $\mathrm{CD}_{133^{+}}$nestin ${ }^{+}$ precursors was enhanced at $5 \%$ oxygen together with the ability of the precursors to generate all three CNS lineages. Raising oxygen tension to $20 \%$ depleted precursor and promoted astrocyte differentiation even in the presence of mitogens. When induced to differentiate by mitogen withdrawal, precursors expanded in $5 \%$ oxygen generated 17 -fold more oligodendrocytes than cells expanded in $20 \%$ oxygen (Pistollato et al., 2007). These data demonstrate that the multi-lineage competence of human CNS precursors and the selective differentiation of oligodendrocytes are regulated by dynamic changes in oxygen tension: lower oxygen tension maintains and expands nestin-positive precursors that exhibit enhanced stem cell properties, while higher oxygen tensions promote p53 phosphorilation and astrocyte differentiation. It seems that differentiation is the main response of human SVZ precursors to $20 \%$ oxygen; higher proportion of oligodendrocytes 
are generated from human CNS precursor cells grown in lowered oxygen and an enhanced differentiation of these cells is found after switching to $20 \%$ oxygen. Oxygen tension influences human CNS precursors and oligodendrocyte fate at multiple stages, suggesting that regulating oxygen may be critical to cell replacement for demyelinating disorders.

$\mathrm{HIF}-1 \alpha$ can also be activated by non-hypoxic factors; on theses basis, several hypoxia-mimetics (such as deferoxamine, ciclopiroxolamine, cobalt chloride, etc.) were evaluated for their capacity to enhance in vitro proliferation, neurogenesis and dopaminergic differentiation of human foetal mesencephalic NPCs. HIF-stabilizing agents or conditions can rescue impaired neurons and promote neurogenesis in vitro, and iron depletion by chelators mimics hypoxia in NPCs (Milosevic et al., 2009). Pharmacological HIF-1 $\alpha$ stabilization may cause a variety of biological effects on ex vivo expanded human neural progenitor cells setting the bases for important future therapeutic applications.

Neural stem cells constitute a promising source of cells for the treatment of several neurological diseases. A great promise is held for their transplantation concerning Parkinson's disease; however, a protocol for controlled dopaminergic differentiation is not yet available. Lowered oxygen tension $\left(3 \% \mathrm{O}_{2}\right)$ enhances dopaminergic differentiation and survival of NSCs in human ventral mesencephalic stem cell line. Dopaminergic neurons experience a higher level of oxidative stress due to the formation of free radicals and other reactive oxygen species, suggesting that dopaminergic neurons may benefit from low oxygen conditions. Noteworthy is the discovery that in low-oxygen conditions a glia-like stem population of the carotid body proliferates and generates new dopaminergic neurons, representing in vivo neurogenesis from adult stem cells derived from the neural crest. The cells extracted from the carotid body and cultured under hypoxic conditions express the progenitor marker nestin and proliferate to form multicell spheres where a small percentage of these cells self renew. These cells become TH-positive and have the same response as normal glomus cells: hypoxia causes them to become depolarized (a lineage resembling that of CNS stem cells) and to secrete dopamine, indicing that neurogenesis of the carotid body requires hypoxia.(Krabbe et al., 2009).

\section{Notch and HIF-1 tango together in hypoxic response}

Great attention and importance has been focused on the role and function of HIF-1 in regulating hypoxic response, but recently Notch signalling has been catching up as another important pathway that might contribute to the development of a dedifferentiated hypoxic phenotype. In many cell types, active Notch signalling is associated with immature, proliferating cells, and it leads to the down-regulation of differentiation-promoting factors of the bHLH type. Hypoxia blocks neuronal differentiation in a Notch-dependent manner, activating Notch-responsive promoters and increasing expression of Notch direct down-stream genes through elevation of its ligands and receptors (Gustafsson et al., 2005; "as reviewed in Bray, 2006"). In the canonical hypoxic response, hypoxia acts by altering the stability and activity of HIF- $1 \alpha$, leading to binding of HIF- $1 \alpha$ to HRE-containing regulatory elements in specific target genes and activation of such genes (Fig. 1 and 7). Hypoxia increases the half-life of Notch, an effect that requires the presence of HIF-1 $\alpha$; there is a physical interaction between HIF-1 $\alpha$ and Notch intracellular domain. These data suggest a new mode of action of HIF-1 $\alpha$ under hypoxia that differs from the classical response (dimerization with HIF-19), proposing a model in which HIF-1 $\alpha$, once stabilized by hypoxia, interacts with Notch enhancing the transcriptional activity of the complex through the recruitment of other activators(Fig. 7). There is strong evidence for a mechanism of cross talk between Notch and $\mathrm{HIF}-1 \alpha$ signalling pathways, and the link between hypoxia and Notch may have ramifications for other aspects of hypoxia, such as tumour development, in which deregulation of both HIF$1 \alpha$ and Notch-mediated signalling events have been implicated (Zhang et al., 2008).

\section{Along the route of hypoxia}

Hypoxia-induced biochemical and molecular changes are highly conserved across species from lower organisms to higher animals. In comparison to evolved vertebrates, less evolved species are able to better survive in hypoxia/anoxia conditions. The pleiotropic nature of these responses suggests a lineagedependent component of how oxygen regulates neural cells and NSC cell fate; however, this has been difficult to ascertain since the effects of changing oxygen tension have not been tested at defined steps in CNS expansion and differentiation or on distinct CNS precursor subtypes within the same tissue. Even though the HIF transcriptional complex is widely conserved among mammalian species and invertebrate organisms (e.g. Drosophila Melanogaster and Caenorhabditis elegans), phylogenetic analyses of HIF proteins indicate a bio-separation of invertebrates from vertebrates. Flies and worms have a single PHD family member, called eg/9, whereas the genomes of higher metazoans contain three paralogous $P H D$ genes (Kaelin and Ratcliffe, 2008). Multi-cellular organisms need to maintain oxygen homeostasis during development, and in particular during neural differentiation. Given the crucial role of HIF in responding to hypoxia, HIF alterations are supposed to disrupt developmental pathways. However, in worms and flies, the inactivation of single $H I F \alpha$ homolog is compatible with several developmental processes, even though such animals are vulnerable to hypoxia. On the other hand, inactivation of the HIF hydroxylase eg/9 may lead to more important developmental abnormalities (Kaelin and Ratcliffe, 2008). These informations suggest that HIF and HIF prolyl hydroxylases are dispensable in these species under non-stressed conditions. These mechanisms are different from those of mammalian organisms where HIF inactivation leads to un-correct developmental processes, suggesting that hypoxia may act as a guiding signal, or that hypoxia pathways are coopted by other signals.

To date, more than 60 HIF-target genes have been identified, whose expression influences processes such as angiogenesis, erythropoiesis, as well as cell survival and proliferation; it has been suggested that (apart from inducing pro-proliferative proteins such as IGF-2, IGF-BP 1-3 and TGF) the HIF pathway includes responses with adverse effects on cell function by inducing cellcycle arrest-specific and pro-apoptotic proteins. The HIF system transactivates a pathway that encompasses many physiological responses to hypoxia, ranging from mechanisms that increase cell survival to those inducing cell cycle arrest (Acker and Acker, 2004). In the mammalian brain, sub-sets of neurons in vivo adapt to condition of moderate hypoxia, leading to a continuous partial 


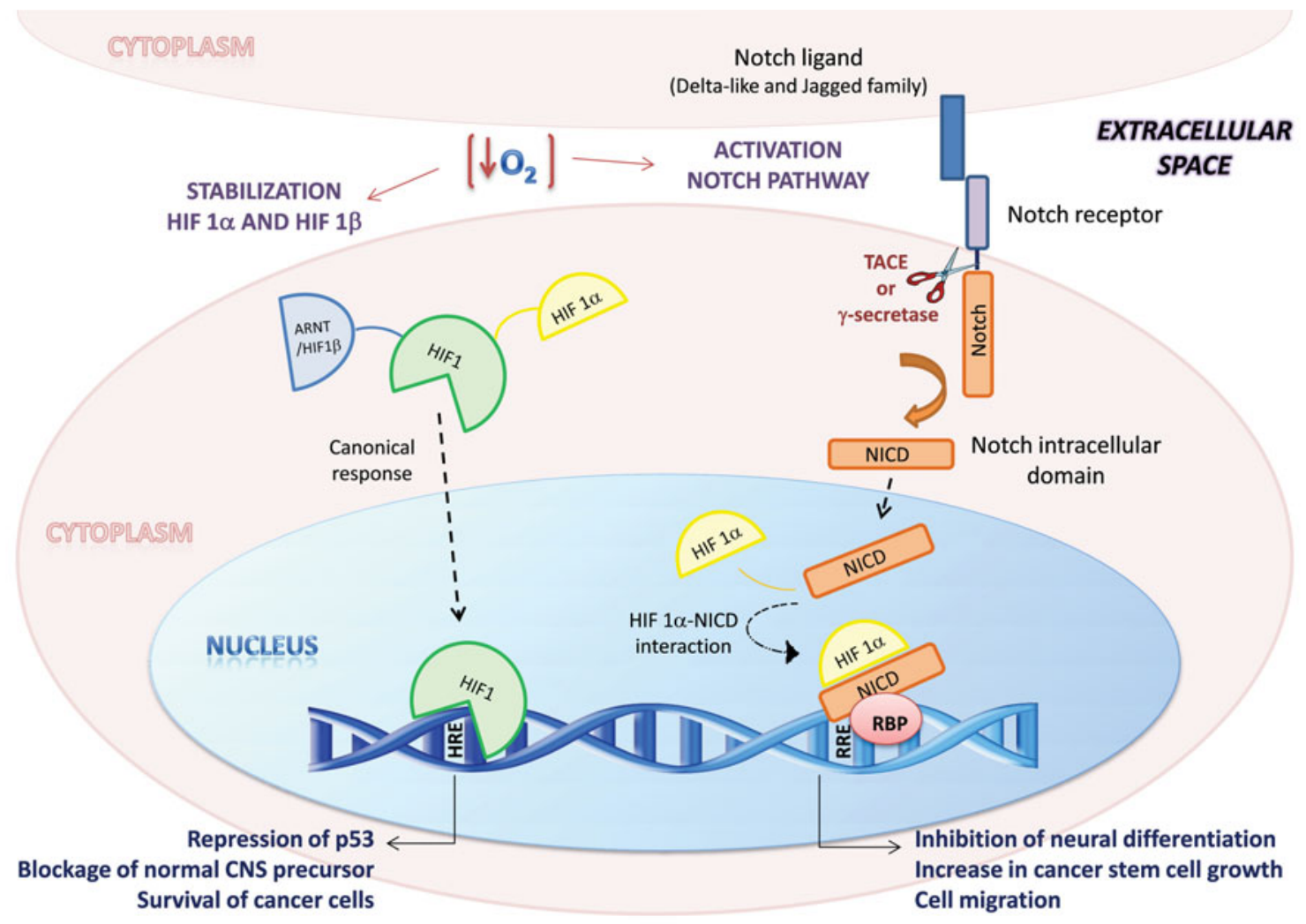

... BRAIN CANCER STEM CELLS?

Fig. 7. Schematic representation of new proposed model of interaction between hypoxia-inducible factor1 (HIF-1) and Notch in hypoxic response and their possible implications in cancer stem cell biology. In canonical response, hypoxia induces activation and stabilization of HIF $1 \alpha$ and ARTN/HIF-1 $\beta$ with formation of HIF-1 heterodimer that goes into the nucleus, resulting in transcriptional repression of p53, blockage of normal NSC precursors and cellular survival (see also Fig. 1). Hypoxia also induces the expression of the endothelial cell Notch ligand (Delta-like and Jagged family) and exposition of Notch receptors on cell surface, leading to increased Notch signaling from neighboring cells. Through Tumor Necrosis Factor$\alpha$ Converting Enzyme (TACE) or $\gamma$-secretase, Notch domain has been cleaved off, releasing Notch intracellular domain (NICD) which migrates into the nucleus, interacts with HIF $1 \alpha$ (and other transcriptional factors), inducing the inhibition of neural differentiation, the increase in cancer stem cell growth, the cell migration and finally resulting in metastasis formation and tumoral poor prognosis.

activation of HIF-1 regulated transcriptional program. How this state of adaptation to physiological hypoxia compares with the properties of cultured neurons adapted to atmospheric oxygen tension has not been yet carefully examined. One possible mechanism is that excess oxygen induces free radical formation that promotes insult to the brain often linked to apoptotic cell death and cellular senescence. In this respect, recent studies implicate oxygen tension and redox state as regulators of neural precursor metabolism, survival and fate. In many cases, cell fate may involve a combination of ROS-mediated effects and altered intracellular oxygen/hypoxia-response signalling "as reviewed in (Panchision, 2009)". However, oxygen has differing effects depending on precursor type (Gustafsson et al., 2005) and atmospheric oxygen might be harmful for neural precursor and stem cells, initiating a variety of cellular events, including loss of proliferation, cell-cycle arrest, cell maturation, senescence and apoptosis.

Generally speaking, culture conditions with oxygen levels $<10 \%$ are often considered hypoxic; however, in the case of brain cells, these conditions more closely simulate a physiological environment. Oxygen lowered to more physiological levels alters cultured CNS progenitors, providing marked trophic and proliferative effects on CNS precursors, and modifying developmental pathways and outcomes. $\mathrm{O}_{2}$ levels much lower than those traditionally used in culture allow improved precursor cell proliferation and provide a powerful tool for the generation of specific neuron types. Oxygen seems to be an important factor contributing to the fate of NSCs; reduced oxygen levels maintain neural precursors in their undifferentiated state, while high oxygen concentrations induce cellcycle arrest, senescence, cellular maturation and finally apoptosis "as reviewed in (Panchision 2009"; Zhang et al., 2006). Lowered oxygen tensions are a more physiologically relevant approach for in vitro analysis and manipulation of CNS precursors. Dynamic variation of oxygen tension may be a critical component in developing effective cellular therapies for demyelinating disorders, and endogenous oxygen-sensitive regenerative capacity in the CNS may suggest that clinical modulation of oxygenation after stroke may be important for stem cell recruitment and neurogenesis. Lowered oxygen conditions favour neural precursors and stem cells, suggesting that a suitable level of hypoxia could be a useful tool for expansion of NPCs for ex vivo therapy and for a better understanding of neural developmental mechanisms "as reviewed in (Acker and Acker, 2004; Studer et al., 2000). 


\section{What about hypoxia and brain cancer stem cells?}

An important aspect that should be taken into consideration is the fine however strong link that connects stem cells with cancer cells. The "cancer stem cell theory" poses that cancers develop from a subset of malignant cells that possess stem cell characteristics, and has been proposed to account for the development of a variety of malignancies, including brain tumors. These cancer stem cells have characteristics of both stem and cancer cells: they have the properties of self-renewal, asymmetric cell division, resistance to apoptosis, independent growth, tumorigenicity and metastatic potential. To date, evidence indicates that brain tumours might derive from the transformation of undifferentiated precursor cells, which are found not only in germinal regions of the developing and early-postnatal CNS, but also in areas of the mature brain, in which neurogenesis persists throughout adulthood. The finding that adult germinal, neural precursors might provide the origin of brain tumour stem cells indicates the presence of common regulatory pathways. Hypoxia actually correlates positively with tumour aggressiveness and it has been causally linked to increased genomic instability:n respect to tumour condition, hypoxia and HIF- $1 \alpha$ can repress p53, a major effector of mitotic arrest and apoptosis (Zhang and Hill, 2004), and HIF-1 $\alpha$ activity can block normal CNS precur- sor differentiation (Gustafsson et al., 2005); hypoxia selectively suppresses mitotic arrest or apoptosis in a pre-existing primitive tumour cell population, rather than promoting dedifferentiation of mature cells, complementing evidence that cancer is caused by dysregulated stem cells(Fig. 8). It has been suggested that progressively low oxygen tensions are more permissive for cancer stem cell survival and self-renewal; lower oxygen tension may synergize with mitotic signals, initiating a negative feedback of differentiation signals and reinforcing an environment for aggressive tumour growth "as reviewed in (Panchision 2009)". In fact, hypoxia alters the expression of differentiation marker genes in neuroblastoma cells, in that the tumour cells adjust to the hypoxic environment by down-regulating genes associated with a neuronal phenotype, and up-regulating genes associated with a neural-like phenotype. As there is a correlation in neuroblastoma between low stage of differentiation and aggressive clinical stage, it can be suggested that dedifferentiation of neuroblastoma cells in hypoxic tumour regions contributes to the malignancy of the tumour. The role of hypoxia has been also investigated in directed migration of NSCs to glioma, finding that hypoxia led to up-regulation of CXCR4, urokinase-type plasminogen activator receptor, VEGF receptor, matrix metalloproteinases, angiopoietin, finally determining NSC tropism to glioma (Zhao et al., 2008). On the other side, the Notch

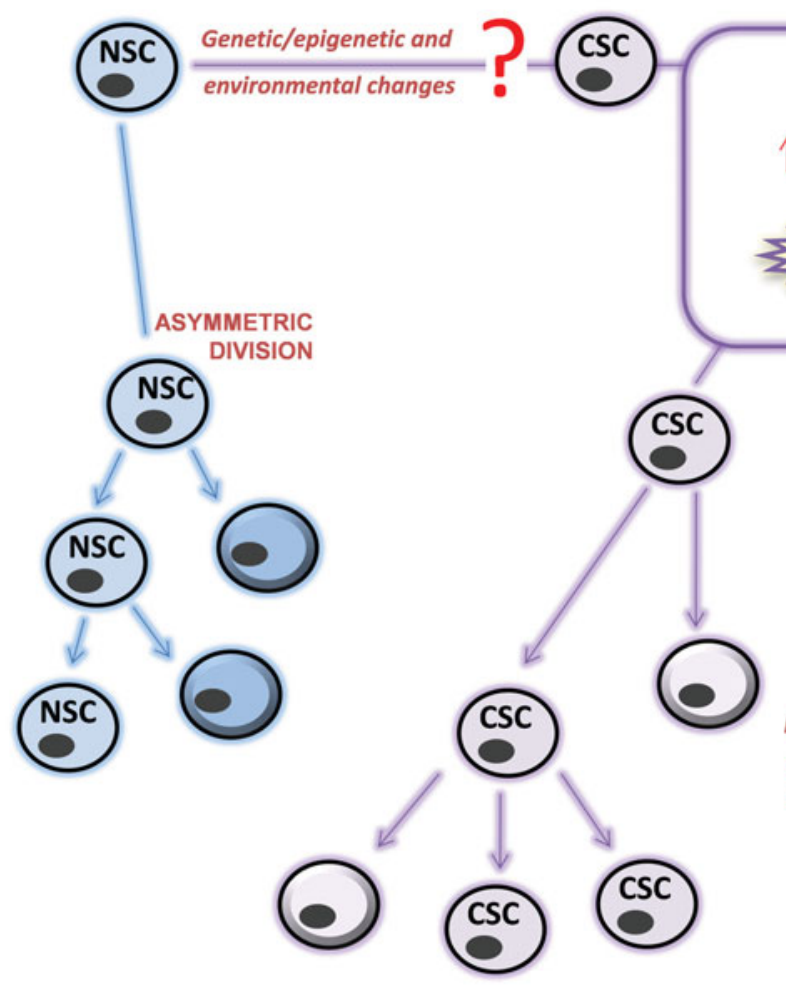

Tumour with poor clinical outcome

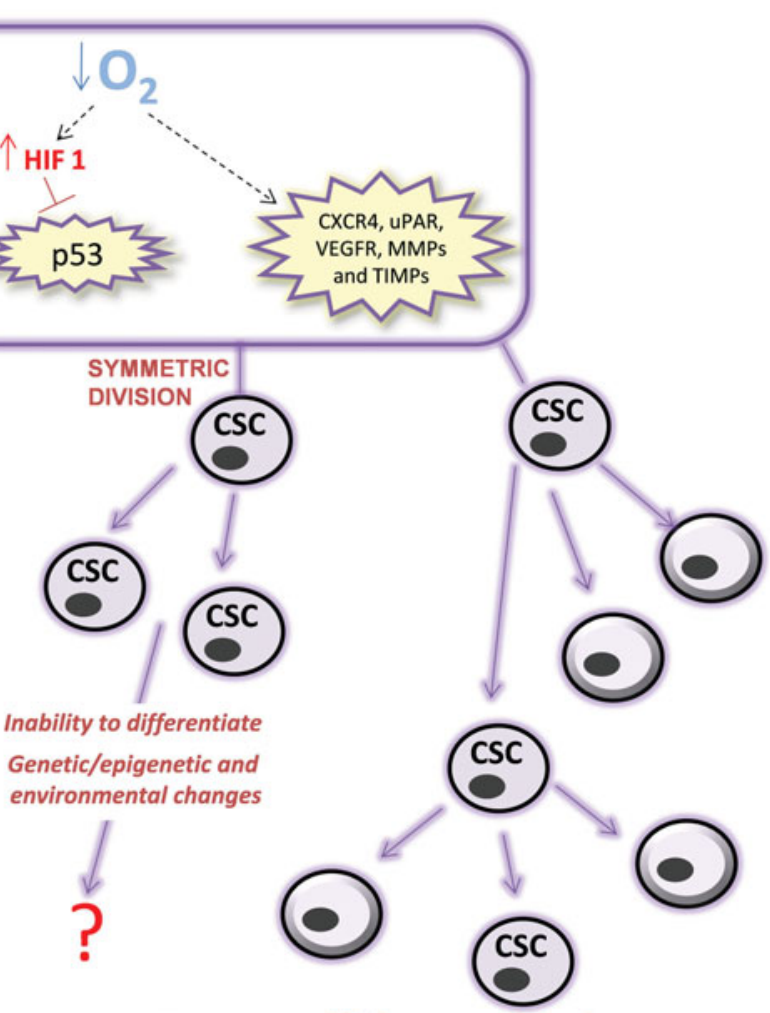

Tumour with better clinical outcome

ASYMMETRIC > SYMMETRIC DIVISION

Fig. 8. Alternative models explaining how brain tumours initiate and develop. Normal brain stem cells typically divide slowly and retain the capacity of self-renewal. Asymmetric division of a stem cell produces one daughter stem cell and one committed progenitor cell. The latter undergoes a limited series of divisions, maintaining a "stable" number of stem cells. However, a stem cell may undergoes oncogenic transformation losing important homeostatic control mechanisms. The genetic/epigenetic and environmental changes leading to the switch from stem cells to cancer stem cells are not actually known; however, hypoxic conditions cause the repression of p53 and modulation of CXCR4, uPAR, VEGFR, Wnt/9-catenin, Notch, MMPs and TIMPs, which are able to influence the self-renewal-differentiation-proliferation of cancer stem cells. 
pathway plays an important role during cell-fate specification in the developing mammalian nervous system; during neocortical development, Notch signalling inhibits neuronal differentiation and maintains the neural stem/progenitor cell pool to allow neurogenesis. Notch plays important roles also in brain tumor biology; stem-like cells in brain tumors share many similarities with neural stem/ progenitor cells and may require Notch for their repair and growth (Zhang et al., 2008). So the understanding of Notch signalling in neoplastic and non-neoplastic stem/progenitor populations will help to unravel important mechanisms influencing developmental and stem cell biology, leading to more effective therapies for brain tumors (Pierfelice et al., 2008) (Fig. 7).

Increasing research demonstrated that certain cancers contain multipotent NSC-like cells with tumor-initiating ability, which may originate malignancy; HIF-1 is a crucial factor in tumour cell adaptation to hypoxic stress and regulates genes involved in important biological processes. The expression of the DNA mismatch repair system is down-regulated in human stem cells cultured in hypoxia $\left(1 \% \mathrm{O}_{2}\right)$, which correlates with lower DNA repair activity in NSCs (Rodriguez-Jimenez, 2008). So, a hypoxic microenvironment creates a hyper-mutagenic state in cancer cells, and leads to lower DNA repair activity in NSCs; on these bases, monitoring the status of DNA repair machinery in hypoxic conditions may contribute to better present and use cell therapies as promising nanomedicines.

In general, normal stem cells accomplish their self-renewal and differentiation capacities by asymmetric cell division, where the stem cell divides generating one stem cell with self-renewal capacity (maintaining a stable number of stem cells) and one daughter cell that subsequently differentiates. However, cancer stem cells can increase their number dividing symmetrically, either because they reside in a polar environment and are exposed to different cues that induce alternative fates, or because genetic/epigenetic modifications can lead to symmetric division (e.g., aberrant DNA methylation, abnormal RNA interference and chromatin remodelling). Cancer stem cells use different self-renewal strategies that allow modulation of their number, cell proliferation and tumour relapse. It is yet unknown if cancer stem cell homeostasis is maintained by asymmetric cell divisions, or by a strategy that uses symmetric cell division to balance cancer stem cells and a more differentiated progeny. Cancer stem cells use symmetric divisions at a much higher rate as compared to their normal counterparts to expand their pool or to generate more differentiated progeny. A pool of cancer stem cells with equivalent developmental potential may produce only new cancer stem cells in some divisions and only more differentiated progeny in others. Symmetric division may lead to developmental plasticity, enhanced growth and regenerative capacity as well as an increased risk of cancer. Cancer stem cells may use either symmetric division, or a combination of symmetric and asymmetric division; the choice between these possibilities may depend on the activation of different developmental mechanisms, which include hormonal (FGF, EGF), and signalling pathways (Notch, NFkB), involved in the control of self-renewal and differentiation of cancer stem cells (Fig. 8) (for a comprehensive overview of hypoxic conditions and cancer stem cells, see Heddleston et al., 2010).

Hypoxia stands at the crossroads of fundamental mechanisms: it promotes the proliferation of NSCs from both the peripheral nervous system and CNS of mammalian organisms; lowered oxygen condition enhances neuronal, especially dopaminergic, differentiation of CNS precursors. These observations suggest that hypoxia can promote proliferation and modify the cell fate of NSCs, resulting useful for the expansion of NSCs for ex vivo cell therapy and for studying neural development (Mannello et al., 2007). On the other side, hypoxic conditions influence several mechanisms involved in neural stem cell-derived cancer, leading to the initiation, development, invasiveness of neural tumours. These results have significant implications not only for understanding the effects of hypoxia in NSC physiology, but also for trying to define the best culture conditions in order to maintain NSC in their physiological condition, thinking that what is normoxic for most cells, may not be normoxic for NSCs. Finally, the deeper knowledge of mechanisms underlying hypoxic responses in NSCs may be fundamental for optimizing ex vivo production methods for cell replacement approaches and for developing stem cell-mediated tumour-selective gene therapies.

\section{References}

ACKER, T. and ACKER, H. (2004) Cellular oxygen sensing need in CNS function: physiological and pathological implications. J. Exp. Biol. 207: 3171-3188.

BRAHIMI-HORN, M.C. and POUYSSEGUR, J. (2009) HIF at a glance. J. Cell Science 122: 1055-1057.

BRANICKY, R.S. and SCHAFER, W.R. (2008) Oxygen homeostasis: how the worm adapts to variable oxygen levels. Curr. Biol. 18: R559-560.

BRAY, S.J. (2006) Notch signalling: a simple pathway becomes complex. Nat. Rev. Mol. Cell Biol. 7: 678-689.

BÜRGERS, H.F., SCHELSHORN, D.W., WAGNER, W., KUSCHINSKY, W. and MAURER, M.H. (2008) Acute anoxia stimulates proliferation in adult neural stem cells from the rat brain. Exp. Brain. Res. 188: 33-43.

CACCI, E., VILLA, A., PARMAR,.M, CAVALLARO, M., MANDAHL, N., LINDVALL, O., MARTINEZ-SERRANO, A. and KOKAIA, Z. (2007) Generation of human cortical neurons from a new immortal fetal neural stem cell line. Exp. Cell Res. 313:588-601.

CHANG, A.J. and BARGMANN, C.I. (2008) Hypoxia and the HIF-1 transcriptional pathway reorganize a neuronal circuit for oxygen-dependent behavior in Caenorhabditis elegans. Proc. Natl. Acad. Sci. USA 105: 7321-7326.

CHEN, H.L., PISTOLLATO, F., HOEPPNER, D.J., NI, H.T., MCKAY, R.D.G. and PANCHISION, D.M. (2007) Oxygen tension regulates serviva and fate of mouse central nervous system precursors at multiple levels. Stem Cells 25: 2291-2301.

CLARKE, L. and VAN DER KOOY, D. (2009) Low oxygen enhances primitive and definitive neural stem cell colony formation by inhibiting distinct cell death pathways. Stem Cells 27: 1879-1886.

CUMMINS, E.P. BERRA, E., COMERFORD, K. M., GINOUVES, A., FITZGERALD, K. T., SEEBALLUCK, F., GODSON, C., NIELSEN, J. E., MOYNAGH, P., POUYS SEGUR, J. and TAYLOR, C. T. (2006) Prolyl hidroxylase-1 negatively regulates IkB kinase-9, giving insight into hypoxia-induded NFkB activity. Proc. Natl. Acad. Sci. USA 103: 18154-18159.

FELLING, R.J., SNYDER, M.J., ROMANKO, M.J., ROTHSTEIN, R.P., ZIEGLER, A.N., YANG, Z., GIVOGRI, M.I., BONGARZONE, E.R. and LEVISON, S.W. (2006) Neural stem/progenitor cells participate in the regenerative response to perinatal hypoxia/ischemia. J. Neurosci. 26: 4359-4369.

GALLI, R., GRITTI, A., BONFANTI, L. and VESCOVI, A.L. (2003) Neural stem cells: an overview. Circ. Res. 92: 598-608.

GUSTAFSSON, M.V., ZHENG, X.,PEREIRS, T., GRADIN. K., JIN, S., LUNDKVIST, J., RUAS, J.L., POELLINGER, L., LENDAHL, U. ad BONDENSSON, M. (2005) Hypoxia requires notch signalling to maintain the undifferentiated cell state. Dev. Cell. 9: 617-628.

HEDDLESTON, J.M, LI, Z., LATHIA, J.D., HJELMELAND, A.B. and RICH, J.N. (2010) Hypoxia inducible factors in cancer stem cells. Br. J. Cancer 102: 789-795.

HORIE, N., SO, K., MORIYA, T., KITAGAWA, N., TSUTSUMI, K., NAGATA, I. and SHINOHARA, K. (2008) Effects of oxygen concentration on the proliferation and differentiation of mouse neural stem cells in vitro. Cell Mol. Neurobiol28: 833-845.

JIN, K., MAO, X.O., SUN, Y., XIE, L. and GREENBERG, D. A. (2002a) Stem cell 
factor stimulates neurogenesis in vitro and in vivo. J. Clin. Invest. 110: 311-319.

JIN, K., MAO, X.O., SUN, Y., XIE, L., NISHI, E., KLAGSBRUN, M. and GREENBERG, D.A. (2002b) Heparin-binding epidermal growth-factor like growth factor: Hypoxiainducible expression in vitro and stimulation of neurogenesis in vitro and in vivo. J. Neurosci. 22: 5365-5373.

JIN, K., MINAMI, M. and LAN, J.Q. (2001) Neurogenesis in dentate subgranular zone and rostral subventricular zone after focal cerebral ischemia in the rat. Proc. Natl. Acad. Sci. USA 98: 4710-4715.

JÖGI, A., VALLO-CHRISTERSSON, J., HOLMQUIST, L., AXELSON, H., BORG, A. and PAHLMA, S. (2004) Human neuroblastoma cells to hypoxia: induction of genes associated with growth, survival, and aggressive behavior. Exp. Cell Res. 295: 469-487.

KEWLEY, R.J., WHITELAW, M.L. and CHAPMAN-SMITH, A. (2004) The mammalian basic helix-loop-helix/PAS family of transcriptional regulators. Int. J. Biochem. \& Cell. Biol. 36: 189-204.

KIM, T.S., MISUMI, S., JUNG, C.G., MASUDA, T., ISOBE, Y., FURUYAMA, F., NISHINO, H. and HIDA, H. (2008) Increase in dopaminergic neurons from mouse embryonic stem cell-derived neural progenitor/stem cells is mediated by hypoxia inducible factor-1 $\alpha$. J. Neurosci. Res. 86: 2353-2362.

KOONG, A.C., CHEN, K.Y. and GIACCIA, A.J. (1994) Hypoxia causes the activation of nuclear factor kappa through the phosphorylation of IKBa on tyrosine residues. Cancer Res 54:1425-30.

KRABBE, C., COURTOIS, E., JENSEN, P., JORGENSES, J.R., ZIMMER, J., MARTINEZ-SERRANO, A. and MEYER, M. (2009) Enhanced dopaminergic differentiation of human neural stem cells by synergistic effect of $\mathrm{Bcl}-\mathrm{X}_{\mathrm{L}}$ and reduced oxygen tension. J. Neurochem. 110: 1908-1920.

LIU YV and SEMENZA, G. L. (2007) RACK1 vs. HSP90: competition for HIF-1 alpha degradation vs. stabilization. Cell Cycle. 6: 656-659.

MANNELLO F and TONTI GA. (2007) Concise review: no breakthroughs for human mesenchymal and embryonic stem cell culture: conditioned medium, feeder layer, or feeder-free; medium with fetal calf serum, human serum, or enriched plasma; serum-free, serum replacement nonconditioned medium, or ad hoc formula? All that glitters is not gold! Stem Cells 25: 1603-1609.

MAZUMDAR, J., DONDETI, V. and SIMON, M.C. (2009) Hypoxia-inducible factors in stem cells and cancer. J. Cell Mol. Med. 13: 4319-4328.

MILISEVIC, J., ADLER, I., MANAEKO, A., SCHWARZ, S.C., WALKINSHAW, S.C., AREND, M., FILIPPIN, L.A., STORCH, A., and SCHWARZ, J. (2009) Non-hypoxic stabilization of hypoxia-inducible factor alpha (HIF-alpha): relevance in neural progenitor/stem cells. Neurotox. Res. 15: 367-380.

MILOSEVIC, J., MAISEL, M., WEGNER, F., LEUCHTENBERG, J., WEGNER, R.H., GERLACH, M., STORCH, A. and SCHWARZ, J. (2007) Lack of hypoxia-inducible factor- $1 \alpha$ impairs midbrain neural precursor cell involving vascular endothelial growth factor signalling. J. Neurosci. 27: 412-421.

PANCHISION, D.M. (2009) The role of oxygen in regulating neural stem cells in development and disease. J. Cell. Physiol. 220: 562-568.

PIERFELICE, T.J., SCHRECK, K.C., EBERHART, C.G. and GAIANO, N. (2008) Notch, neural stem cells, and brain tumors. Cold Spring Harb. Symp. Quant. Biol. 73: 367-375

PISTOLLATO, F., CHEN, H.L., SCHWARTZ, P.H., BASSO, G. and PANCHISION, D.M (2007) Oxygen tension controls the expansion of human CNS precursors and the generation of astrocytes and oligodendrocytes. Mol. Cell. Neurosci. 35: 424-435.

RODRIGUEZ-JIMENEZ, F.J., MORENO-MANZANO, V., LUCAS-DOMINGUEZ, R. and
SANCHEZ-PUELLES, J.M. (2008) Hypoxia causes downregulation of mismatch repair system and genomic instability in stem cells. Stem Cells 26: 2052-2062.

SCHOFIELD, C.J. and RATCLIFFE, P.J. (2004) Oxygen sensing by HIF hydroxylases. Nat. Rev. Mol. Cell. Biol. 5: 343-354.

SHINGO, T., SOROKAN, T., SHIMAZAKI, T. and WEISS, S. (2001) Erythropoietin regulates the in vitro and in vivo production of neuronal progenitors by mammalian forebrain neural stem cells. J. Neurosci. 21: 9733-9743.

SILVERMAN-GAVRILA, L.B., LU, T.Z., PRASHAD, R.C., NEJATBAKHSH, N., CHARLTON, M.P. and FENG, Z. P. (2009) Neural phosphoproteomics of a chronic hypoxia model-Lymnaea stagnalis. Neurosci. 161: 621-634.

SKUL'SKII, I.A., PIVOVAROVA, N.B., GAPON, S.A. and KOROTKOV, S.M. (1991) The effect of anoxia and energy metabolism inhibitors on potassium and sodium homeostasis in the neurons of the gastropod mollusk. Neirofiziologiia23:313-321.

STUDER, L., CSETE, M., LEE, S.H., KABBANI, N., WALIKONIS, J., WOLD, B. and MCKAY, R. (2000) Enhanced prolifetaion, survival, and dopaminergic differentiation of CNS precursor in lowered oxygen. J. Neurosci. 20: 7377-7383.

SUNG, S.M., JUNG, D.S., KWON, C.H., PARK, J.Y., KANG, S., K. and KIM, Y.K (2007) Hypoxia/reoxygenation stimulates proliferation through PKC-dependent activation of ERK and Akt in mouse neural progenitor cells. Neurochem. Res. 32: $1932-1939$.

THEUS, M.H., WEI, L., CUI, L., FRANCIS, K., HU, X., KEOGH, C. and YU, S.P. (2008) In vitro hypoxic preconditioning of embryonic stem cells as a strategy of promoting cell survival and functional benefits after transplantation into the ischemic rat brain. Exp. Neurobiol. 210: 656-670.

TONTI GA and MANNELLO F (2008) From bone marrow to therapeutic applications: different behaviour and genetic/epigenetic stability during mesenchymal stem cell expansion in autologous and foetal bovine sera? Int. J. Dev. Biol. 52: 1023-1032.

TONTI GA, MANNELLO F, CACCI E and BIAGIONI S. (2009) Neural stem cells at the cross road: MMPs may tell the way. Int. J. Dev. Biol. 53: 1-17

XIONG, L., ZHAO, T., HUANG, X., LIU, Z.H., ZHAO, H., LI, M.M., WU, L. Y., SHU, H.B. ZHU, L.L. and FAN, M. (2009) Heat shock protein 90 is involved in regulation of hypoxia-driven proliferation of embryonic neural stem/progenitor cells. Cell Stress and Chaperones 14: 183-192.

XU, Q., WANG, S., JIANG, X., ZHAO, Y., GAO, M., ZHANG, Y., WANG, X., TANO, K. KANEHARA, M., ZHANG, W. and ISHIDA, T. (2007) Hypoxia-induced astrocytes promote the migration of neural progenitor cells via vascular endothelial factor, stem cell factor, stromal-derived factor- $1 \alpha$ and monocyte chemoattractant protein-1 upregulation in vitro. Clin. Exp. Pharmacol. Physiol. 34: 624-631.

ZHANG, C.P., ZHU, L.L., ZHAO, T., ZHAO, H., HUANG, X., MA, X., WANG, H. and FAN, M. (2006) Characterization of neural stem cells expanded in lowered oxygen and the potential role of hypoxia-inducible factor-1alpha. Neurosignals 15:259-265.

ZHANG, X.P., ZHENG, G. and LOU, L. (2008) Notch activation promotes cell proliferation and the formation of neural stem cell-like colonies in human glioma cells. Mol. Cell. Biochem. 307: 101-108.

ZHAO, D., NAJBAUER, J., GARCIA, E., METZ, M.Z., GUTOVA, M., GLACKIN, C.A., KIM, S.U. and ABOODY, K.S. (2008) Neural stem cell tropism to glioma: critical role of tumor hypoxia. Mol. Cancer Res. 6: 1819-1829.

ZHOU, L. and MILLER, C.A. (2006) Mitogen-activated protein kinase signalling, oxygen sensors and hypoxic induction of neurogenesis. Neurodegener. Dis. 3: 50-55.

ZHOU, J., SCHMID, T., FRANK, R. and BRUNE, B. (2004) PI3K/Akt is required for heat shock proteins to protect HIF-1alpha from $\mathrm{pVHL}$-independent degradation. J. Biol. Chem. 279: 13506-13513. 


\section{Further Related Reading, published previously in the Int. J. Dev. Biol.}

Gene expression in the placenta: maternal stress and epigenetic responses

Ciprian P. Gheorghe, Ravi Goyal, Ashwani Mittal and Lawrence D. Longo

Int. J. Dev. Biol. (2010) 54: 507-523

Modeling and quantification of cancer cell invasion through collagen type I matrices

Olivier De Wever, An Hendrix, Astrid De Boeck, Wendy Westbroek,Geert Braems, Shahin Emami, Michèle Sabbah, Christian Gespach and Marc Bracke

Int. J. Dev. Biol. (2010) 54: 887-896

Placental metabolic reprogramming: do changes in the mix of energy-generating substrates modulate fetal growth?

Nicholas P. Illsley, Isabella Caniggia and Stacy Zamudio

Int. J. Dev. Biol. (2010) 54: 409-419

Induction of neural crest cells from mouse embryonic stem cells in a serum-free monolayer culture

Yuko Aihara, Yohei Hayashi, Mitsuhi Hirata, Nobutaka Ariki, Shinsuke Shibata, Narihito Nagoshi, Mio Nakanishi, Kiyoshi Ohnuma, Masaki Warashina, Tatsuo Michiue, Hideho Uchiyama, Hideyuki Okano, Makoto Asashima and Miho Kusuda Furue Int. J. Dev. Biol. (2010) 54: 1287-1294

Activated Notch1 is a stronger astrocytic stimulus than leukemia inhibitory factor for rat neural stem cells Nidia S. Rodríguez-Rivera, Anayansi Molina-Hernández, Erika Sánchez-Cruz, Diana Escalante-Alcalde and Iván Velasco Int. J. Dev. Biol. (2009) 53: 947-953

Reprogramming of melanoma cells by embryonic microenvironments

Alejandro Díez-Torre, Ricardo Andrade, Cristina Eguizábal, Elixabete López, Jon Arluzea, Margarita Silió and Juan Aréchaga Int. J. Dev. Biol. (2009) 53: 1563-1568

Using fruitflies to help understand the molecular mechanisms of human hereditary diffuse gastric cancer Joana Caldeira, Paulo S. Pereira, Gianpaolo Suriano and Fernando Casares

Int. J. Dev. Biol. (2009) 53: 1557-1561

A critical role for myoglobin in zebrafish development

Danielle H. Vlecken, Janwillem Testerink, Elisabeth B. Ott, Philippe A. Sakalis, Richard T. Jaspers and Christoph P. Bagowski Int. J. Dev. Biol. (2009) 53: 517-524

Characterization of Hypoxia induced gene 1: expression during rat Central Nervous System maturation and evidence of antisense RNA expression

Gabriela Bedó, Marcelo Vargas, María-José Ferreiro, Cora Chalar and Daniella Agrati Int. J. Dev. Biol. (2005) 49: 431-436

$$
5 \text { yr ISI Impact Factor }(2010)=2.86
$$

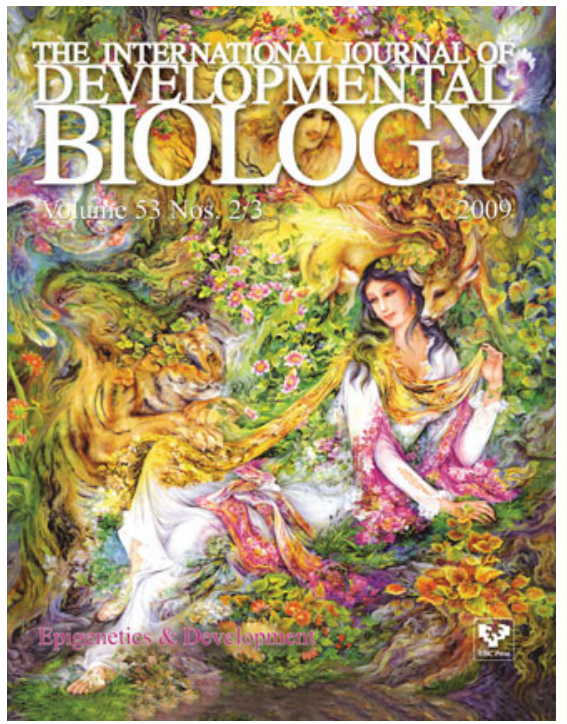

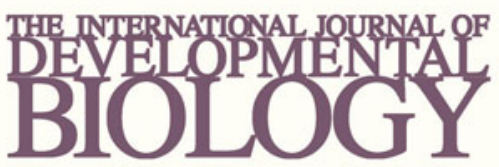

Volume 54 Nos. 6/7
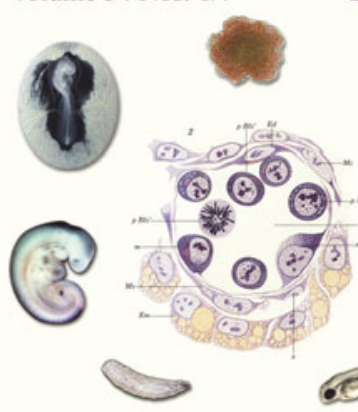

Developmental Hematopoiesis
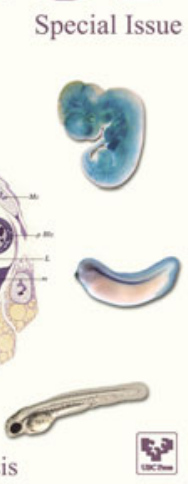

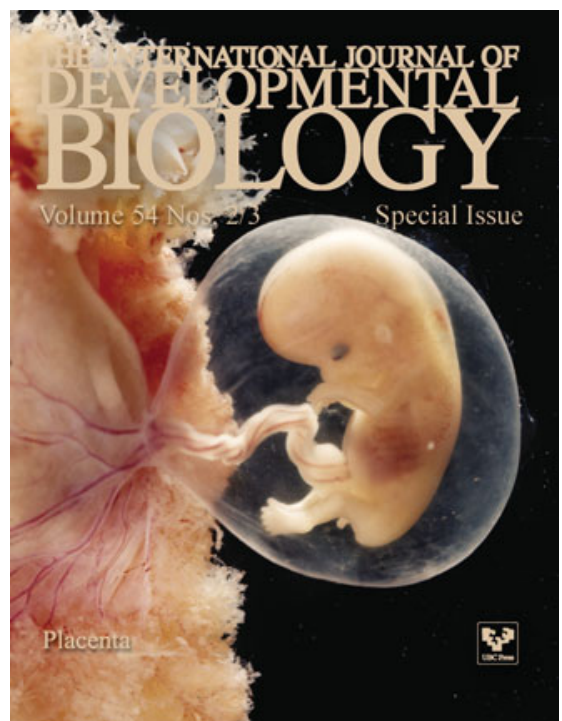

